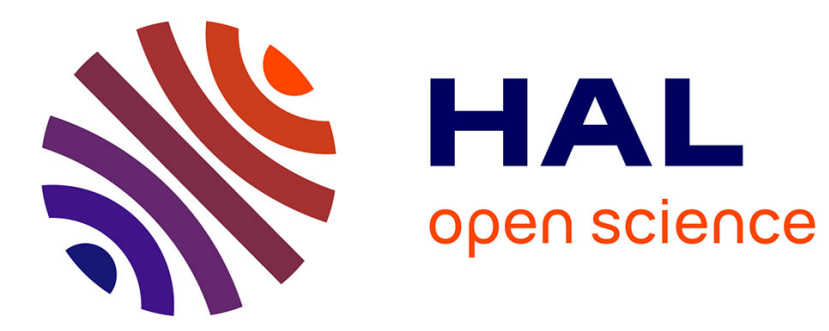

\title{
Epitaxial growth of CdTe oriented thin films, infrared characterization and possible applications to photo-voltaic cells
}

\author{
X. Gerbaux, A. Pianelli, A. Hadni, C. Jeanniard, P. Strimer
}

\section{To cite this version:}

X. Gerbaux, A. Pianelli, A. Hadni, C. Jeanniard, P. Strimer. Epitaxial growth of CdTe oriented thin films, infrared characterization and possible applications to photo-voltaic cells. Revue de Physique Appliquée, 1980, 15 (3), pp.573-577. 10.1051/rphysap:01980001503057300 . jpa-00244763

HAL Id: jpa-00244763

https://hal.science/jpa-00244763

Submitted on 1 Jan 1980

HAL is a multi-disciplinary open access archive for the deposit and dissemination of scientific research documents, whether they are published or not. The documents may come from teaching and research institutions in France or abroad, or from public or private research centers.
L'archive ouverte pluridisciplinaire $\mathbf{H A L}$, est destinée au dépôt et à la diffusion de documents scientifiques de niveau recherche, publiés ou non, émanant des établissements d'enseignement et de recherche français ou étrangers, des laboratoires publics ou privés. 


\title{
Epitaxial growth of CdTe oriented thin films, infrared characterization and possible applications to photo-voltaic cells
}

\author{
X. Gerbaux $\left({ }^{*}\right)$, A. Pianelli $\left({ }^{* *}\right)$, A. Hadni $\left({ }^{*}\right)$, C. Jeanniard $\left({ }^{*}\right)$ and P. Strimer $\left({ }^{*}\right)$ \\ $\left(^{*}\right)$ Laboratoire Infrarouge Lointain. ERA, C.N.R.S., no 14. Université de Nancy I, C.O. $n^{\circ}$ 140, 54037 Nancy Cedex, France \\ (**) Laboratoire de Métallurgie. LA, C.N.R.S., $\mathrm{n}^{\circ}$ 159. Institut National Polytechnique de Lorraine. Parc de Saurupt, \\ 54042 Nancy Cedex, France
}

(Reçu le 27 juillet 1979, révisé le 10 décembre 1979, accepté le 12 décembre 1979)

\begin{abstract}
Résumé. - Des films minces orientés de CdTe, d'épaisseur comprise entre 0,1 et $10 \mu \mathrm{m}$, sont obtenus par épitaxie en phase vapeur. Le substrat est un monocristal de CdTe cubique dont la face (111), polie mécaniquement et décapée chimiquement, est préalablement recouverte d'une couche épitaxique mince de $\mathrm{NaCl}$. Les films épitaxiques de CdTe obtenus sur ce substrat sont détachés par dissolution de $\mathrm{NaCl}$ dans l'eau.

Les diffractogrammes de rayons $\mathrm{X}$ et les clichés de Laue montrent que les films de $\mathrm{CdTe}$ et de $\mathrm{NaCl}$ sont cristallisés dans le système cubique et sont orientés parallèlement aux plans (111).

La densité de porteurs libres de chaque film de CdTe est calculée à partir de sa fréquence de plasma qui est donnée par son spectre de transmission infrarouge lointain. La mobilité des porteurs est calculée en fonction de la résistivité électrique du film et de sa densité de porteurs.
\end{abstract}

\begin{abstract}
The growth of CdTe oriented thin films by the ENSH method - i.e. Epitaxial Nucleation in Submicroscopic Holes of an intermediate layer closely applied on a bulk single crystal - has been recently described. The CdTe films are generally difficult to detach from the bulk crystal. However free films are needed to study the infrared transmission in the spectral region of high absorption. To get them, the vitreous or amorphous thin intermediate layers are substituted by quite soluble an oriented $\mathrm{NaCl}$ layer grown from phase vapour on a (111) CdTe bulk crystal surface.

The X-ray diffraction and Laue patterns show that the CdTe thin film grown on the $\mathrm{NaCl}$ intermediate layer is (111) oriented, and also the $\mathrm{NaCl}$ layer which covers the (111) CdTe bulk crystal surface.

The far infrared transmission spectra obtained through the oriented CdTe films give directly the TO phonon frequency for $q=0$ with accuracy.
\end{abstract}

Introduction. - The growth of CdTe films from the vapour phase is difficult not only because of the well known different sticking coefficients of the two elements leading generally to a lack of cadmium, but for other causes giving twins, polymorphs and small crystallites. Most reports found in the literature refer to polycrystalline, non oriented, high resistivity films.

Our purpose was to grow large area $\left(\right.$ several $\left.\mathrm{cm}^{2}\right)$, detachable, oriented thin films of CdTe to look at their infrared transmission. Such films have never been made up to now. In a previous paper [1] concerning both CdSe and CdTe we tried the ENSH method (Epitaxial Nucleation in Submicroscopic Holes) with an intermediate layer deposited on a bulk single crystal made respectively of CdSe or CdTe. With polyimide, carbon and $\mathrm{BeF}_{2}$ intermediate layers, all amorphous or glassy, we could get a variety of pin- holes density depending on the thickness of the layer. For small densities of holes separate nuclei with one orientation are observed. Unfortunately their growth at the surface of the intermediate layer is limited to 2 to $4 \mu$ at most and a continuous film cannot be made. For densities of pin-holes high enough to get an average hole distance of $2-4 \mu$, a continuous oriented film is obtained. Unfortunately the intermediate layer is so thin (i.e. $150 \AA$ ), the links of the oriented film with the bulk single crystal are so many, that it is generally impossible to detache the oriented film.

This paper describes the use of a $\mathrm{NaCl}$ intermediate layer much thicker (i.e. $1000 \AA$ ) on which we have grown large area oriented CdTe films. They are easy to detache by dissolving the $\mathrm{NaCl}$ layer in water. We have been able to study the far infrared transmission to look at the TO phonons at point $\Gamma$ of the Brillouin zone, and at a broad band which can be ascribed 
either to the first interference fringe or to the plasma frequency.

1. CdTe homoepitaxy growth. - It can be done in a very simplified evacuated Jar (Fig. 1). The crucible is at the top with polycrystalline pieces of CdTe. The temperature is increased up to $700^{\circ} \mathrm{C}$ for sublimation.

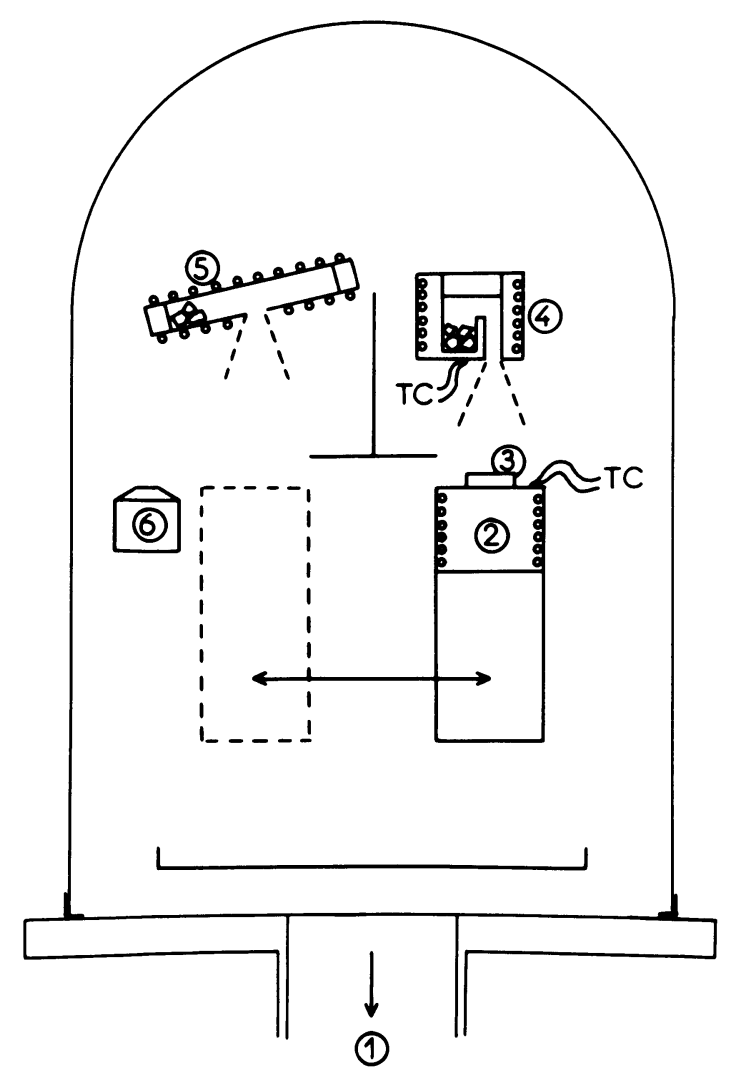

Fig. 1. - Bell jar apparatus for depositing two successive layers on a bulk CdTe single crystal. 1) To liquid nitrogen trap;2) Substrate heater ; 3) Substrate ; 4) $\mathrm{CdTe}$ crucible ; 5) $\mathrm{NaCl}$ crucible ; 6) Quartz microbalance; TC : Thermocouple.

Vapour is deposited on the face (111) of a CdTe single crystal at a $5 \mathrm{~cm}$ distance from the crucible. The surface has been mechanically polished and etched for a few seconds with a solution of Bromine $(5 \%)$ in methyl alcohol.

The pressure is increasing up to $10^{-5}$ torr during evaporation of CdTe. There is a critical temperature $\left(525^{\circ} \mathrm{C}\right)$ to get homoepitaxy. Figure 2 shows pyramidal growth figures with all their basis parallel. Such an homoepitaxy has been described earlier by several authors [2]. However the epitaxial layer cannot be detached from the bulk crystal and cannot be used to get the infrared transmission spectra we needed.

2. CdTe heteroepitaxy growth on a specially prepared $\mathrm{NaCl}$ intermediate layer. - In the same evacuated Jar described above we have first deposited a thin crystalline layer (thickness $e \simeq 0.1 \mu \mathrm{m}$ ) of sodium chloride on the face (111) of a CdTe single crystal

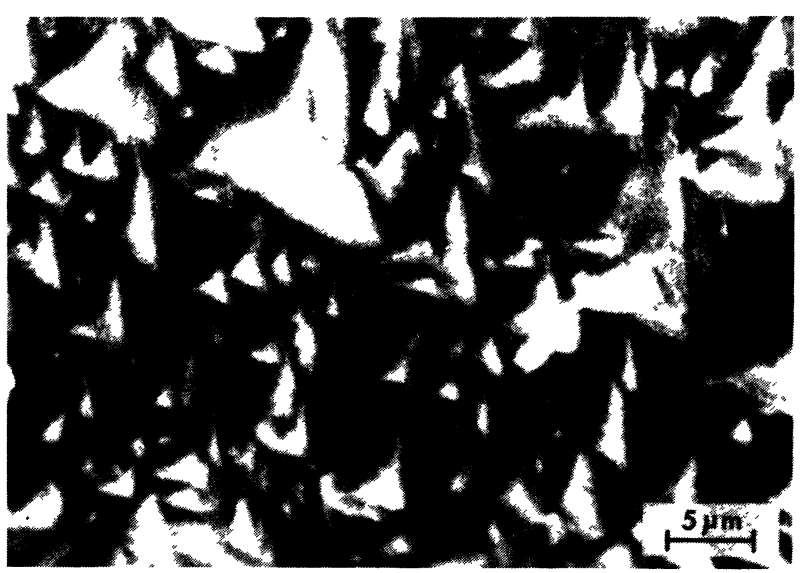

Fig. 2. - CdTe homo-epitaxy on (111) face of a bulk CdTe single crystal.

heated to $525^{\circ} \mathrm{C}$. We shall see further by X-ray diffraction that the $\mathrm{NaCl}$ film is (111) oriented (it should be amorphous if deposited at room temperature). There has been hetero-epitaxy growth of $\mathrm{NaCl}$ on CdTe.

Then $\mathrm{CdTe}$ is evaporated on the $\mathrm{NaCl}$ layer as above on the CdTe bulk crystal and it is also shown by X-ray diffraction that the CdTe film is a blende type oriented one with the same orientation (111) as the single crystal holder. The net result is an heteroepitaxy through an intermediate layer as in the ENSH method [3], but in that case the role of minute pinholes in the intermediate layer has not been demonstrated. Grow th rates in the range of $20-40 \mu \mathrm{m} / \mathrm{h}$ were obtained by varying the source temperature $\left(550-600^{\circ} \mathrm{C}\right)$.

3. X-ray studies of the films. - The X-ray diffraction study is made on a classical goniometer. Both sample and detector are rotated together and different peaks are observed.

When the sample is placed in the normal position, lines of strong intensity corresponding to the cubic CdTe (hhh) lines are observed without any other line corresponding to that phase. This suggests that the $A_{3}$ axis is normal to the film surface. This surface corresponds either to a (111) cadmium layer, or to a (111) tellurium layer. Such an orientation is confirmed by the rocking curves on the CdTe (hhh) lines and on the $\mathrm{NaCl}$ intermediate layer (hhh) lines. Moreover, the parallelism between the CdTe (111) and the $\mathrm{NaCl}$ (111) plane is verified.

The lattice parameter has been determined on one sample (Fig. 3). The cubic phase (hhh) lines lead to $a_{\text {cub }}=(6.482 \pm 0.0008) \AA$ at $23^{\circ} \mathrm{C}$, which is in agreement with the average value $(6.481 \AA)$, obtained by K. Zanio [7].

Beside the CdTe cubic phase (hhh) lines, the same sample shows several lines of much less intensity ascribed to the wurtzite structure hexagonal phase (0001) lines. 


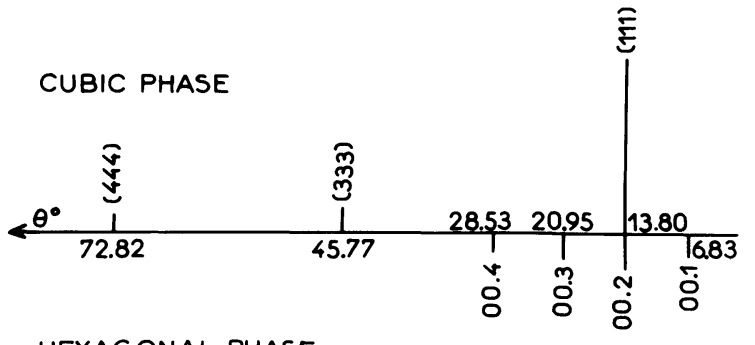

HEXAGONAL PHASE

Fig. 3. - Scheme showing the line positions for cubic and hexagonal CdTe oriented films.

The (0001), (0003) and (0004) lines positions of the cobalt $\mathrm{KX}_{1}$ radiation lead to $C_{\mathrm{hex}}=(7.489 \pm 0.005) \AA$ at $23^{\circ} \mathrm{C}$. In these conditions, the cubic and hexagonal $\mathrm{CdTe}$ phases parameters would be related by

$$
C_{\mathrm{hex}}=2\left(d_{111}\right)_{\mathrm{cub}}=2 a_{\mathrm{cub}} / 3=7.485 \AA .
$$

In conclusion, the $\mathrm{X}$-ray diffraction study shows that the CdTe films are well oriented and essentially formed by close-packed f.c.c. arrangement with an $\mathrm{A}_{3}$ axis normal to the sample surface. There is sometimes a very small proportion of the hexagonal closepacked arrangement.

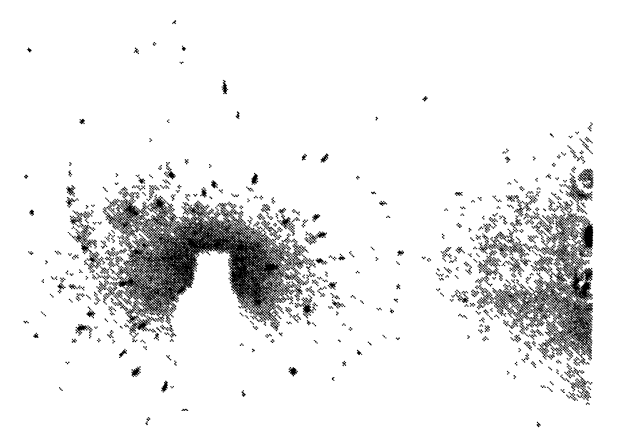

Fig. 4. - X-ray Laue pattern of a bulk CdTe single crystal.

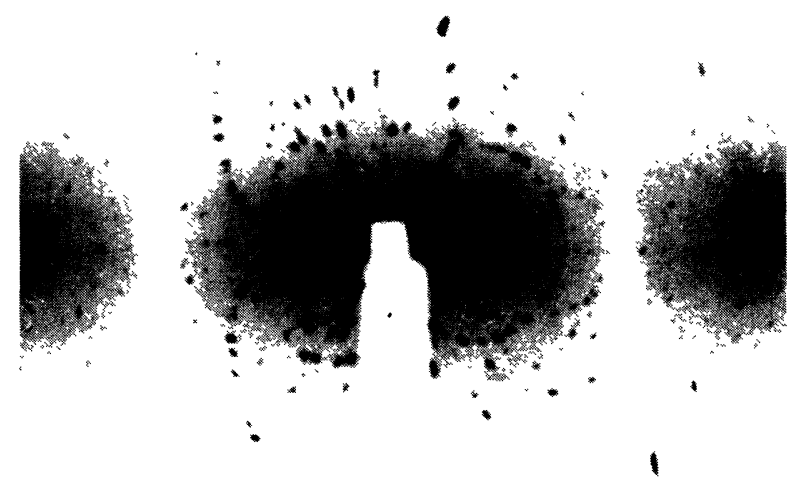

Fig. 5. - X-ray pattern of a thin CdTe film.
We have checked these results by comparing the $\mathrm{X}$-ray reflection Laue patterns given respectively by a CdTe single crystal (Fig. 4) and a thin oriented film (Fig. 5). Both patterns are very similar : the crystallites of the thin films have one orientation.

4. Infrared studies on the CdTe films. - Figure 6 and figure 7 give the transmission spectra of a thin CdTe oriented film in the near infrared (Fig. 6) and around $140 \mathrm{~cm}^{-1}$ where the TO phonon is located for

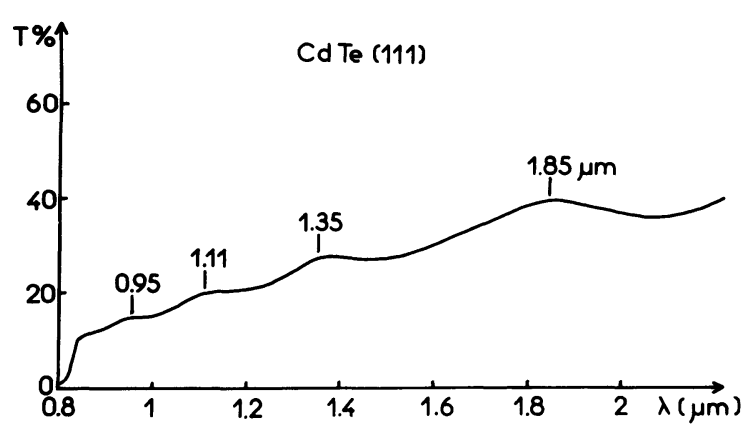

Fig. 6. - Transmission spectrum of a CdTe (111) oriented film glued with nujol on a glass plate, thickness $e \simeq 1 \mu \mathrm{m}$.

a zero wave vector (Fig. 7). On figure 6 we can locate the valence to conduction band transition edge at $0.82 \mu \mathrm{m}$ and see some interference fringes. Assuming a refractive index $n=2.75$ [4], we get the thickness $e$ of the film : $e \simeq 1 \mu \mathrm{m}$. Figure 7 gives the TO phonon frequency for $q=0$ in good accordance with previous studies on unoriented evaporated films $[5,6]$. However the accuracy given by an oriented film is higher and will help to get the parameters of the oscillator at different temperatures.

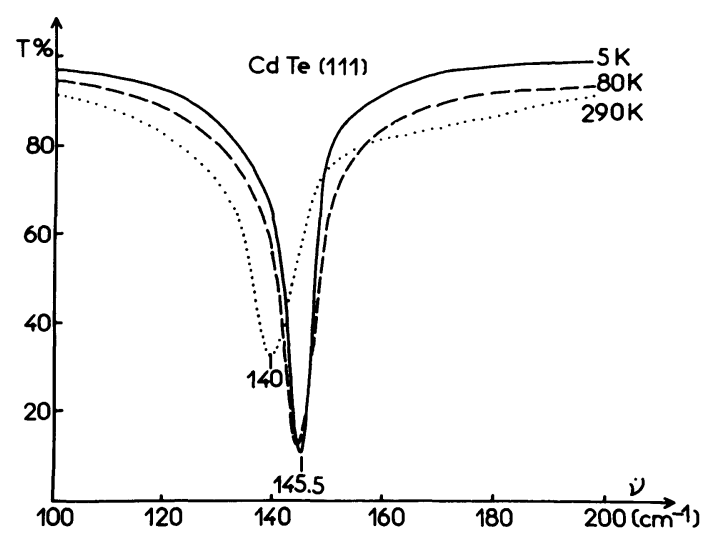

Fig. 7. - Transmission spectrum of a CdTe (111) oriented film glued with nujol on a silicon plate. The half height width is increasing from $6.5 \mathrm{~cm}^{-1}$ at $5 \mathrm{~K}$ to $13 \mathrm{~cm}^{-1}$ at $290 \mathrm{~K}, e \simeq 1 \mu \mathrm{m}$.

Figure 8 gives the transmission of two samples $(e \simeq 10 \mu \mathrm{m})$. The thickness has been chosen to study the $100 \mathrm{~cm}^{-1}$ broad band with the best accuracy. For one film (A) it is located at $120 \mathrm{~cm}^{-1}$, for the other 


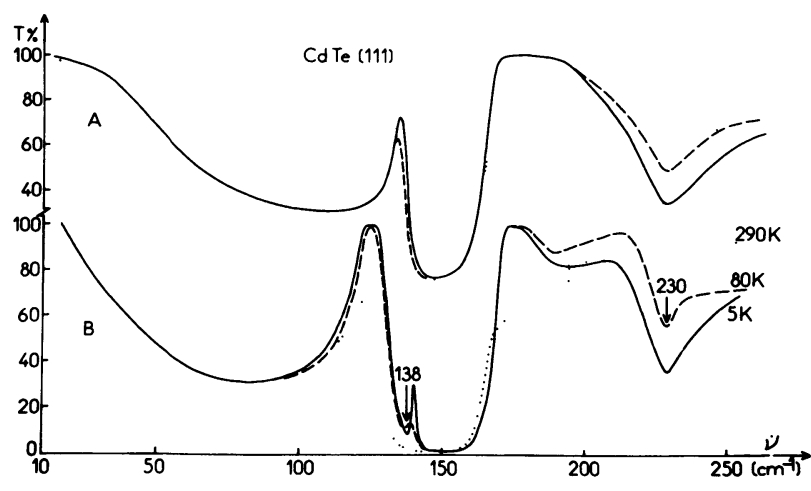

Fig. 8. - Transmission spectra of two CdTe (111) oriented free films, thickness $e \simeq 10 \mu \mathrm{m}$.

one (B) at $85 \mathrm{~cm}^{-1}$. This wide band might be tentatively ascribed to a plasma resonance. Such a resonance is expected in that spectral range. It has been used to get the carrier concentration and even the mobility $[11,12,13]$ in good accordance with determination by Hall effect and resistivity measurements for other semi-conductors such as GaAs [11]. Reflectivity measurements are generally used. The peculiarity of our study is the use of transmission measurements which are available because of the very small thickness of the films we have made. However the transmission is increasing when $\dot{v} \rightarrow 0$ which seems in contradiction with a free-carrier dielectric contribution [see however the case of InSb [14] where reflectivity $R \rightarrow 20 \%$ when $\omega \rightarrow 0$ ]. We must also consider that in paragraph 5 a very low value of the negative carriers mobility is computed :

$$
\mu_{\mathrm{A}}=6.5 \times 10^{-5} \mathrm{~cm}^{2} \cdot \mathrm{V}^{-1} \mathrm{~s}^{-1},
$$

hence a very short electron scattering time :

$$
\tau=\frac{\mu \mathrm{m}^{*}}{e} ; \quad \tau=4 \times 10^{-17} \mathrm{~s},
$$

which should impede the observation of plasma frequencies around $100 \mathrm{~cm}^{-1}$ corresponding to a much larger period, $\tau \simeq 0.3 \times 10^{-12} \mathrm{~s}$ [see however a case of high mobility CdTe [12] where

$$
\tau=1.5 \times 10^{-14} \mathrm{~s}\left(\mu=300 \mathrm{~cm}^{2} / \mathrm{V} . \mathrm{s}\right)
$$

and for which plasma effects have been observed in the far infrared].

Assuming the broad band due to plasma oscillations, let us call $\dot{v}_{\mathrm{P}}$ the frequency of maximum absorption, then the density $\mathrm{N}_{0}$ of carriers is written :

$$
N_{0}=\left[\frac{2 \pi c \dot{v}_{\mathrm{P}}}{e}\right]^{2} m^{*} \varepsilon_{0} \varepsilon_{\mathrm{R}} .
$$

We assume a $n$ doped sample where

$$
m^{*}=0.1 \times 9.1 \times 10^{-31} \mathrm{~kg}
$$

has been measured by cyclotron resonance [7], and $e=1.6 \times 10^{-19} \mathrm{Cb}$. We get respectively

and

$$
N_{0}^{\mathrm{A}}=1.14 \times 10^{17} \mathrm{e} . \mathrm{cm}^{-3}
$$

$$
N_{0}^{\mathrm{B}}=0.57 \times 10^{17} \text { e. } \mathrm{cm}^{-3} .
$$

In both films $\mathrm{A}$ and $\mathrm{B}$, the plasma frequency is temperature independant from 300 to $5 \mathrm{~K}$ and thus the carrier concentration should also be. This seems typical of a doped sample [8] while $N_{0}$ should increase with temperature for an undoped sample. Both samples show an absorption band at $230 \mathrm{~cm}^{-1}$ which might have the same origin as the one previously located at $250 \mathrm{~cm}^{-1}$ and explained as a $\mathrm{LO}+\mathrm{LA}$ absorption band $[4,5]$.

In conclusion, it seems difficult to ascribe the broad band observed in the very far infrared to a plasma resonance because it leads to very small mobilities which should impede such observation. The other alternative is to ascribe it to the first interference fringe. We have to assume a refractive index variation from $n=3.2$ to $n=5$ [4].

5. Electrical measurements. - The electrical resistance of oriented film A has been measured to get resistivity $\rho$. At room temperature

$$
\rho_{\mathrm{A}}=7 \times 10^{5} \Omega . \mathrm{cm} .
$$

This is a very high value, seven orders of magnitude higher than for In doped single crystals. From $\rho$ and from the assumed value of $N_{\mathrm{A}}$, we get the mobility $\mu$ of the carriers,

$$
\mu_{\mathrm{A}}=\frac{1}{\rho_{0} N_{0} e}, \quad \mu_{\mathrm{A}}=6.5 \times 10^{-5} \mathrm{~cm}^{2} \mathrm{~V}^{-1} \mathrm{~s}^{-1}
$$

It is much lower than for stoichiometric single crystals or for the thin $\mathrm{CdTe}$ films deposited on $\mathrm{BaF}_{2}$ freshly cleaved in air with a source of cadmium used during the formation of the layer. Lopez-Otero et al. have obtained mobilities as high as $386 \mathrm{~cm}^{2} / \mathrm{V}$.s and $\rho \simeq 1 \Omega \times \mathrm{cm}$.

The carriers in our samples are probably negative, with a mobility of the same order of magnitude as in Lopez-Otero's samples. The very high resistivity is due to a small concentration of carriers, probably of the order of $10^{-12} \mathrm{~cm}^{-3}$. Hence another argument to say that the broad infrared band is not due to a plasma oscillation.

6. Conclusion. - The preparation of the sample seems a new one : we have made large area oriented thin films of CdTe and they have been detached.

The growth mechanism is not completely understood. There is first epitaxial growth of $\mathrm{NaCl}$ on a (111) 'face of a CdTe bulk single crystal, then epitaxial growth of CdTe (111) on the $\mathrm{NaCl}$ layer. This can be 
explained by the closeness of the parameters of both lattices. The possibility of epitaxial growth of CdTe on $\mathrm{NaCl}$ bulk single crystal is well known [9]. However without special conditions the orientation of the film is far from perfect. Electron bombardement of the $\mathrm{NaCl}$ substrate has been recently shown to be efficient [10]. The good quality of the oriented films we have obtained might be due to the fact that the oriented $\mathrm{NaCl}$ layer was freshly grown.

The CdTe films we have made show a remarkable orientation, and due to the thinness of the films, we have obtained accurate infrared transmission spectra. A broad band observed in the far infrared has been ascribed to the first interference fringe. The plasma frequency is not observable. The resistivity is very high due to a lack of stoichiometry. Hall measurements are needed to get the concentration of carriers but they are difficult to get because of the high resistivity. The aim of the study was only to get oriented films. A parallel orientation of the grains is a good way to reduce boundaries effects. We think that mobilities are high in our films. The next step is to increase carrier concentration either by In doping or by a better stoichiometry, or both. The preparation of thin, oriented, detachable, films of CdTe with high mobilities seems feasible and a new interest in CdTe photovoltaic cells is possible.

Acknowledgments. - The authors are pleased to thank professor J. Aubry for suggesting the use of $\mathrm{NaCl}$ to make intermediate layers, professor $\mathrm{A}$. Herold and Mrs M. Lelaurain for the Laue patterns observations, professor B. Roques and Mr. A. Kohler for Scanning Electron Micrographs. We are also much grateful to Dr Marfaing for pertinent discussions which have been a stimulus in this study and an introduction to the physics of photo-voltaic cells, and to Dr. Triboulet for the growth of the bulk CdTe single crystal.

\section{References}

[1] Gerbaux, X., Hadni, A. and Strimer, P., Thin Solid Films 67 (1980) 117.

[2] Mimila-Arroyo, J., Bouazzi, A. and Cohen-Solal, G., Revue Phys. Appl. 12 (1977) 423.

[3] Gerbaux, X. and Hadni, A., J. Cryst. Growth 47 (1979) 593.

[4] Danielewicz, E. J. and Coleman, P. D., Appl. Opt. 13 (1974) 1164.

[5] Bottger, G. L. and Geddes, A. L., J. Chem. Phys. 47 (1967) 4858 .

[6] Manabe, A., Mitsuishi, A. and Yoshinaga, H., Japan J. Appl. Phys. 6 (1967) 593.

[7] Zanio, M. K., Semiconductors and Semimetals (Cadmum Telluride, Acad. Press, New York) vol. 13, 1978.
[8] Lopez-Otero, A., J. Cryst. Growth 45 (1978) 214.

[9] Novik, F. T., Rumsh, M. A. and Zimkina, T. M., Sov. Phys. Crystallogr. 8 (1963) 295.

[10] Shimaoka, G., J. Cryst. Growth 45 (1978) 313.

[11] Sobota, H., Neumann, H., Muller, A. and Riede, V., Solid State Electron. 21 (1978) 699.

[12] Perkowitz, S. and Thorland, R. H., Phys. Rev. B 9 (1974) 545.

[13] Amirtharaj, P. M., Bean, B. L. and Perkowitz, S., J. Opt. Soc. Amer. 67 (1977) 939.

[14] Yoshinaga, H. and Oetuen, R. A., Phys. Rev. 101 (1956) 526. 